\title{
Assessment of antifungal activity of some boletes mushrooms found in Himalayan range of Pakistan against some fungi
}

\author{
Farwa Batool $^{1}$, Samina Sarwar ${ }^{*}$, Khajista Jabeen ${ }^{1}$, Tooba Shafiq ${ }^{1}$ and \\ Abdul Nasir Khalid ${ }^{2}$ \\ 1. Department of Botany, Lahore College for Women University, Lahore-Pakistan \\ 2. Department of Botany, University of the Punjab, Lahore-Pakistan \\ *Corresponding author's email: samina_boletus@yahoo.com \\ Citation \\ Farwa Batool, Samina Sarwar, Khajista Jabeen, Tooba Shafiq and Abdul Nasir Khalid. Assessment of \\ antifungal activity of some boletes mushrooms found in Himalayan range of Pakistan against some fungi. Pure \\ and Applied Biology. Vol. 8, Issue 4, pp2257-2261. http://dx.doi.org/10.19045/bspab.2019.80171

\begin{tabular}{|c|c|c|c|}
\hline Received: 24/05/2019 & Revised: 19/07/2019 & Accepted: 22/07/2019 & Online First: $27 / 07 / 2019$ \\
\hline
\end{tabular}

\section{Abstract}

Ectomycorrhizal mushrooms belonging to Boletales (Basidiomycota) viz. Boletus edulis Bull, Hortiboletus rubellus Krombh and Suillus sibiricus Singer were selected to evaluate their antifungal potential against some filamentous fungi viz. Aspergillus terreus Thom, Aspergillus niger Tiegh and Rhizopus stolonifer Vuill. Extracts of these selected mushrooms were prepared in methanol and their various concentrations $(0 \%, 1 \%, 1.5 \%, 2 \%$ and $3 \%)$ were tested against selected pathogenic fungi. $B$. edulis showed maximum decline (51-53\%) in the biomass of R. stolonifer, S. Sibiricus showed 40-45\% decline in biomass of A. terreus, while all the concentrations of $H$. rubellus showed 50-55\% decline in the biomass of $A$. niger. Present work revealed that selected indigenous mushrooms have strong antifungal potential against different pathogenic fungi. So, these mushrooms can be used as source material for fungal control methods.

Keywords: Ascomycetes; Boletales; Ectomycorrhizal fungi

\section{Introduction}

Fungi consist of a large group of eukaryotic organisms comprising more than 1,500,000 species [1]. Most species are usually used as a source of food whereas some fungi are mostly pathogenic to different organisms including plants [2] i.e., Aspergillus terreus causes damage to wheat and ryegrass as well as foliar blight of potatoes; Rhizopus stolonifer is saprophytic to bread [3]; A. terreus and $A$. niger are destroying over 125 million tons of rice, wheat, potato, maize and soya bean every year [4]. A. niger can also cause black mold on plants [5].

Contrastingly, macromycetes fungi have known antitumor, antifungal, antibacterial activities due to their chemical composition
[6]. They constitute ectomycorrhizal association with the roots of higher plants. Boletus edulis, Hortiboletus rubellus and Suillus sibiricus included in order Boletales are ectomycorrhizal, medicinal fungi. $B$. edulis is well known edible mushroom and in many parts of the world it is used as an important food source [7]. Their chemical composition makes them an antifungal agent. These mushrooms were collected from moist temperate Himalayan range of Pakistan and identified by morphological and molecular methods by first author [8] and for present research work these are selected to evaluate their antifungal potency against some pathogenic micromycetes. 
Materials and methods

Selection of mushrooms

Ectomycorrhizal fungi (mushrooms) Hortiboletus rubellus, Boletus edulis and Suillus sibiricus used in the present work were identified by morphological and molecular methods by first author [8]. So, for the further progress these mushrooms were selected to evaluate their antifungal potential against Aspergillus terreus, Aspergillus niger and Rhizopus stolonifer.

Isolation and characterization of pathogenic fungi

Pure cultures of A. terreus, A. niger and $R$. stolonifer were prepared on $2 \%$ Malt extract agar (MEA) medium. These pure cultures were stored at $4{ }^{\circ} \mathrm{C}$ for further use [9]. In macroscopic characterization of fungal colonies, forms, colour, appearance on medium, margins, growth rate were observed while for microscopic identification slides were prepared by using Mezler's reagent and were observed under compound microscope to visualize their hyphae, conidiophores, conidia, sporangiophore and spores.

\section{Antifungal bioassays}

Antifungal bioassay was conducted by following the protocol set by [10]. Two grams material of tested mushrooms were soaked in $20 \mathrm{ml}$ of methanol separately for 7 days at room temperature and then filtered through an autoclaved muslin cloth. The filtered solutions were allowed to evaporate and after evaporation $0.16 \mathrm{~g}$ gummy mass of $H$. rubellus, B. edulis and S. sibiricus were obtained. $20 \%$ stock solutions were prepared by adding $0.1 \mathrm{ml}$ of distilled water in the respective gummy mass of test mushrooms. These stock extracts were stored at $4^{0} \mathrm{C}$.

Various concentrations viz. 1\%, 1.5\%, 2\%, $3 \%$ were made for each mushroom extract by adding different quantities of stock solutions in flasks. Control treatments were without any mushroom extract. Each concentration was replicated three times and endowed with Chloromycetin capsule @ $50 \mathrm{mg} / 100 \mathrm{ml}$ of medium to avoid bacterial contamination. $5 \mathrm{~mm}$ disc of each test fungus, from the base cultures, was placed in the center of 12 flasks having the mushroom extract $H$. rubellus, B. edulis and $S$. sibiricus. Three replicates were made for each treatment. All these plates were incubated at $25^{\circ} \mathrm{C}$ for one week. After 7 days fungal growth was measured by filtering the solution of each concentration through pre weighed Whatsman no.1 filter paper. The test fungal biomass was allowed to dry in electric oven. Percentage growth inhibition of the test fungal biomass was measured by using the formula:

Growth inhibition $(\%)=$ growth in control - growth in treatment

Growth in control

\section{Results}

Macroscopic and microscopic characterization of test fungi Aspergillus niger

Colony colour: white to yellow with black conidia, Texture: velvety, Growth pattern: regular, Margins: entire, Odour: Pungent, Hyphae thick walled, septate and branched, Conidiophore wide with long stipe, smooth walled and colorless to light brown, Conidia varied in size globose in shape, brown in colour.

\section{Aspergillus terreus}

Colony color: Brown, Growth pattern: Regular, Margins: smooth, Texture: rough, conidiophore thin and postrate, columella spherical, conidia various in number.

\section{Rhizopus stolonifer}

Colony colour: black, Growth rate: rapid, Growth pattern: irregular, Texture: velvety, Odour: pungent, Margins: irregular, stolons prostate and thick walled, hyaline became brown towards nodes. Rhizoids long and brown, Columella brown, spherical, Sporangia spherical in appearance and black, Sporangiophore arise singly from nodes of stolons, Brown, smooth walled and non-septate. 


\section{Antifungal activity of Methanolic extracts of Macromycetes against test fungus}

The effect of different concentrations of methanolic $H$. rubellus, B. edulis and $S$. sibiricus crude extract was inspected against $A$. niger, $R$. stolonifer and $A$. terreus. Out of five concentrations of methanolic extracts of $H$. rubellus i.e. $0 \%$, $1 \%, 1.5 \%, 2 \%, 3 \%$ (Figure 1), the highest percentage showed best result in inhibition growth of $A$. niger up to $55 \%$ more than the control treatment. B. edulis found effective as antifungal agent against $R$. stolonifer and a 53\% decline (Figure 2) in biomass of test fungus was recorded against different concentrations of applied extract. Results obtained by the extract of $S$. sibiricus against $A$. terreus retarded the test fungal biomass up to 54\% (Figure 3). All the results were recorded after 7 days incubation period.

\section{Discussion}

In present study, the methanolic extracts of different concentrations $(0 \%, 1 \%, 1.5 \%$, $2 \%, 3 \%$ ) of $H$. rubellus, S. sibricus and $B$. edulis were used against the target fungi $A$. niger, A. terreus and $R$. stolonifer. All selected mushrooms showed best results in separate pathogenic fungi. All the extract of these mushrooms exhibited strong antifungal activity against test pathogenic fungi. Previously, Ferreira et al. [11] evaluated the antifungal property of two wild edible mushroom species from the North East of Portugal, Lactarius deliciosus and Tricholoma portentosum. Iwalokun et al. [12] studied the antimicrobial potential of two organic extracts of Pleurotus ostreatus and suggested that $P$. ostreatus possesses antimicrobial and antioxidant potentials and reason of these activities is attributed due to the presence of terpenoids, tannins and steroidal glycosides. Ectomycorrhizal mushrooms possess antiallergic, anticarcinogenic, antibacterial, anticoagulant, antifungal, antihypertensive, anti-inflammatory, antinociceptive, antioxidant, antipyretic, antivenom, antiviral properties. Alves et al. [13] suggested that the antifungal activity of mushroom extracts might be due to the presence of sesquiterpene, steroids, organic acids, acylcyclopentenediones and quinoline compounds.

The results of present study showed a maximum inhibition of test fungi (A. niger and $R$. stolonifer), when tested against boletes ( $H$. rubellus and B. edulis). As previously, Elsayed et al. [14] reported the different types of bioactive metabolites and their relevant procedures, as well as the different mechanisms of action of mushroom compounds as potent antifungal and anti-inflammatory agents.

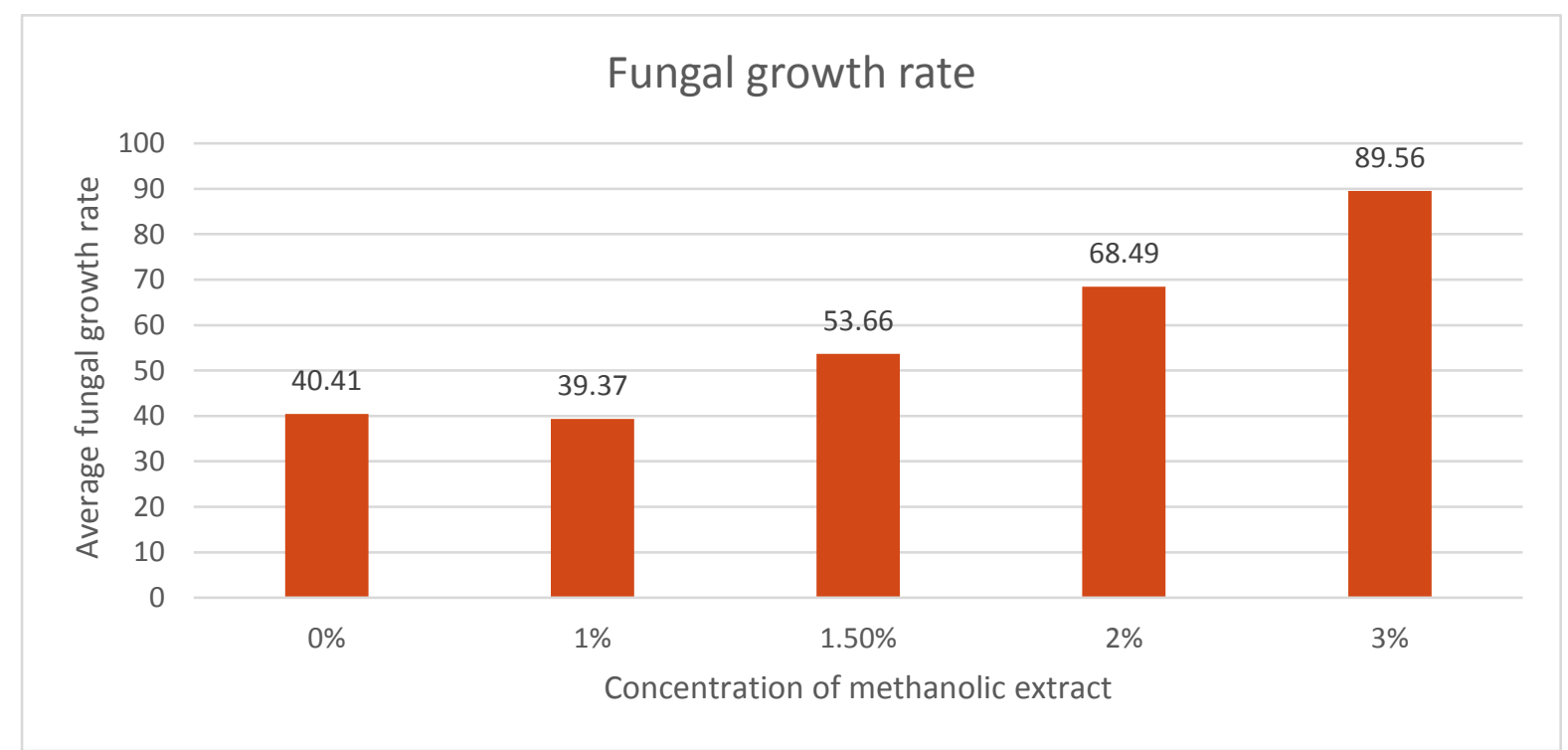

Figure 1. Antifungal activity of Hortiboletus rubellus against Aspergillus niger. 


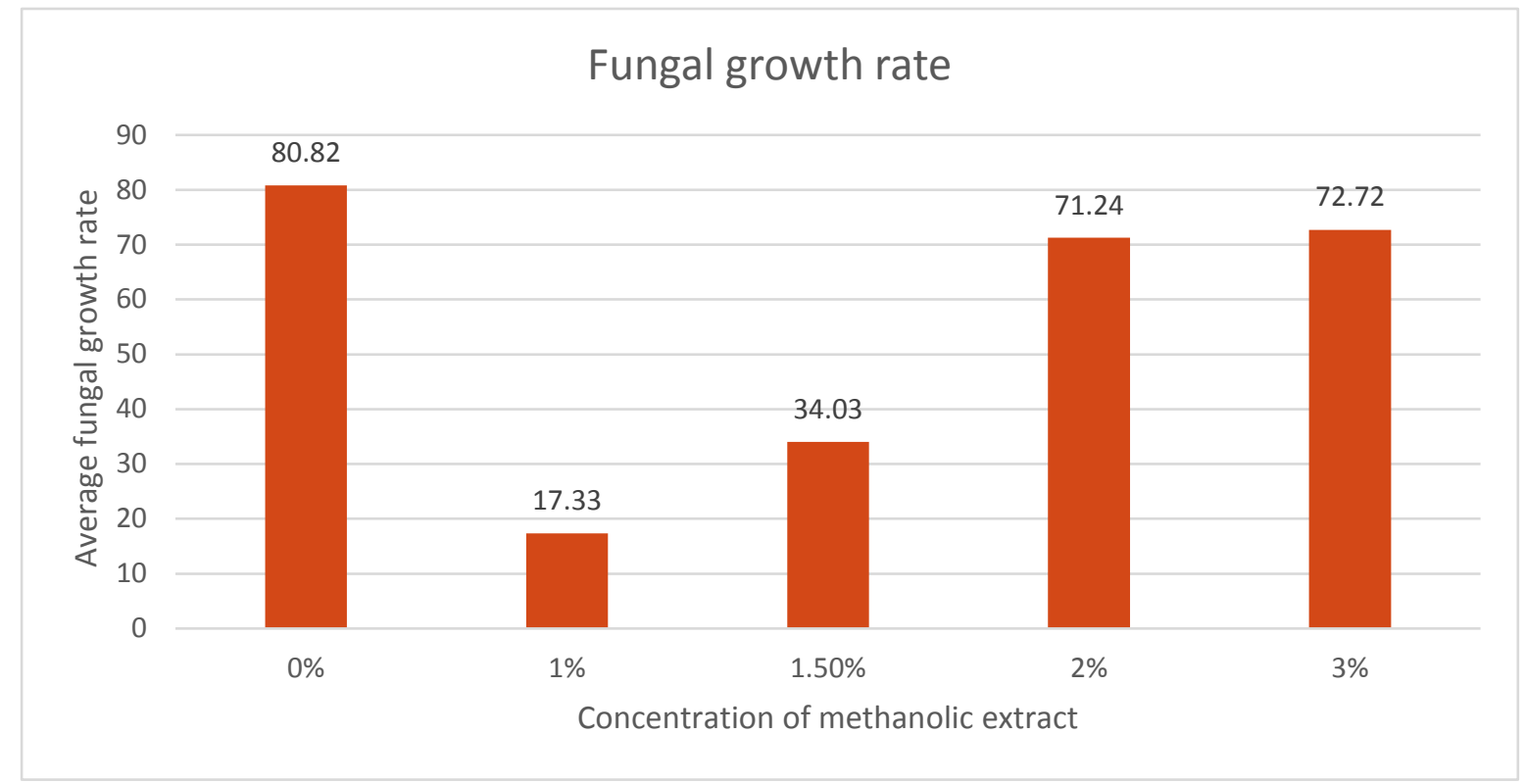

Figure 2. Antifungal activity of Boletus edulis against Rhizopus stolonifer

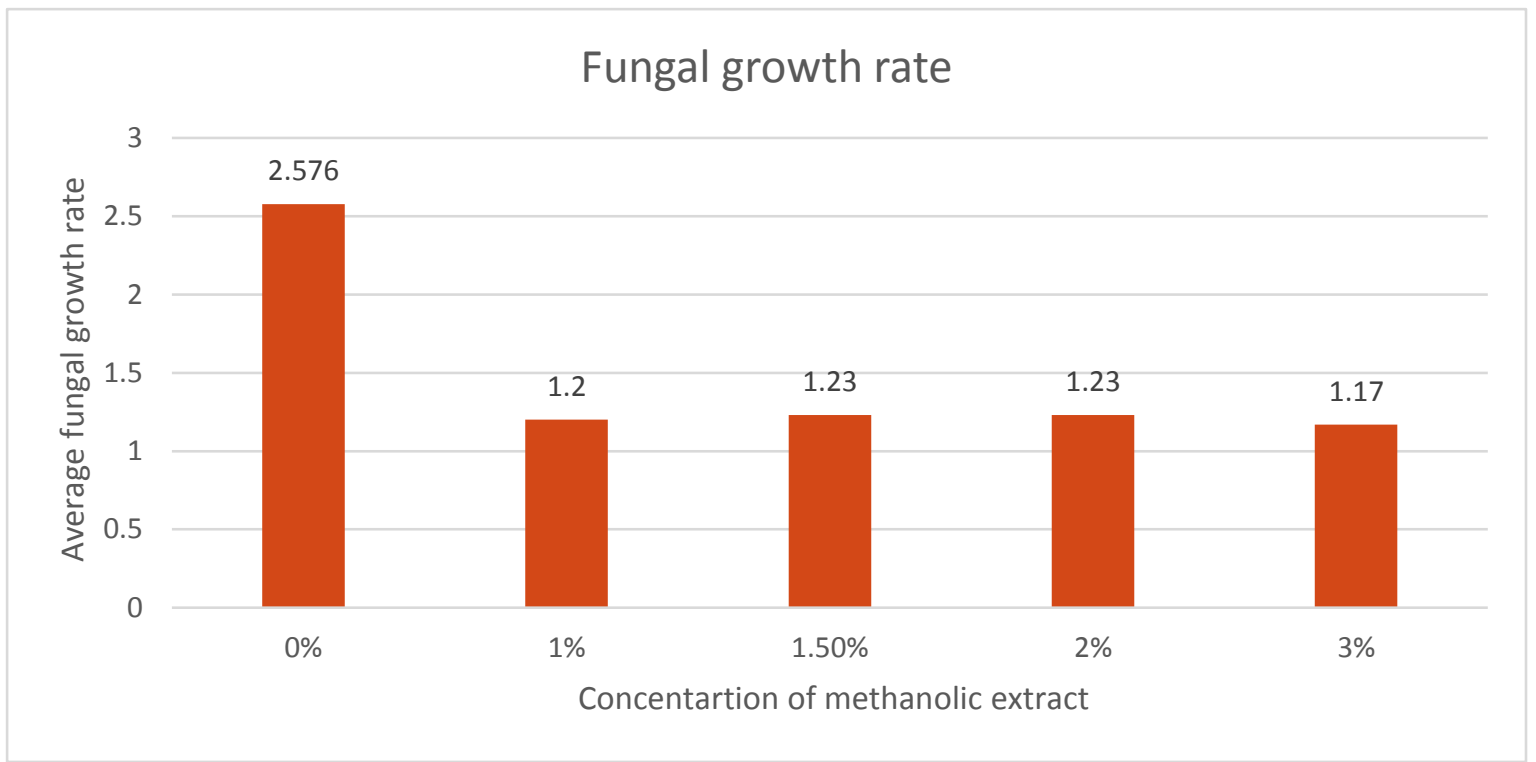

Figure 3. Antifungal activity of Suillus sibiricus against Aspergillus terreus

\section{Conclusion}

This study concludes that methanolic extracts of ectomycorrhizal fungi contain different antifungal substances that showed variable antifungal activity. The antifungal substances are low and high molecular weight compounds. All selected mushrooms have marked antifungal properties against phytopathogenic fungi.

\section{Authors' contributions}

Conceived and designed the experiments: $\mathrm{S}$ Sarwar \& K Jabeen, Performed the experiments: $\mathrm{F}$ Batool \& $\mathrm{T}$ Shafiq, Analyzed the data: S Sarwar \& K Jabeen, Contributed materials/ analysis/ tools: AN Khalid, Wrote the paper: F Batool, S Sarwar, K Jabeen \& T Shafiq. 


\section{References}

1. Heijden VD, Bruin S, Luckerhoff L, Logtestijn RS \& Schlaeppi K (2016). A widespread plant fungal bacterial symbiosis promotes plant biodiversity, plant nutrition and seedling recruitment. ISME J 2: 389-399.

2. Barros L, Calhelha RC, Vaz JA, Ferreria IC, Baptista P \& Estevinho LM (2007). Antimicrobial activity and bioactive compounds of Portuguese wild edible mushrooms Methanolic extracts. Eur Food Res Technol 2: 151156.

3. Lugauskas (2002). Fungi and Food spoilage. $2^{\text {nd }}$ edition, Commonwealth Scientific and Industrial Research organization.

4. Fisher MC, Henk DA, Briggs CJ, Brownstein JS \& Madoff LC (2012). Emerging fungal threats to animal, plant and ecosystem health. Nature 4: 186-194.

5. Hedayati MT, Mohseni B \& Moradi (2004). A survey on the pathogenic fungi in soil samples of potted plants from Sari hospitals, Iran. J Hosp Infect 1: 59-62.

6. Maria JA, Isabel CFR, Ferreira, Joana D, Vania T, Anabela M \& Manuela P (2013). A Review on Antifungal Activity of Mushroom (Basidiomycetes) Extracts and Isolated Compounds. Curr Top Med Chem 21: 49-50.

7. Dimitrijevic M, Jovanovic VS, Cvetkovic J, Mihajilov KT, Stojanovic G \& Mitic V (2015). Screening of antioxidant, antimicrobial and antiradial activities of twelve selected
Serbian wild mushrooms. Anal Methods 10: 4181-4191.

8. Sarwar S (2013). Boletes and their ectomycorrhizal morphotypes from some coniferous forests of Pakistan. $\mathrm{PhD}$ dissetation, University of the Punjab Lahore, Pakistan.

9. Aqsa S, Zeb S \& Khajista J (2016). Antifungal and antioxidant activity of stem bark extracts of Ficus religiosa $\mathrm{L}$. $P A B$ 4:1304-1315.

10. Javaid A \& Samad S (2012). Screening of allelopathic trees for their antifungal potential against Alternaria alternata strains isolated from dying back Eucalyptus spp. Nat Prod Res 26: 1697-1702.

11. Ferreira, M, Jacob KMG, Capelari CC, Rosa M \& Zani CL (2005). Screening of Brazilian basidiomycetes for antimicrobial activity. Mem Inst Oswaldo Cruz 7: 967-974.

12. Iwalokun B, Usen U, Otunba A \& Olukoya D (2007). Comparative phytochemical evaluation, antimicrobial and antioxidant properties of Pleurotus Ostreatus Afr J Biotechnol 15: 17-18.

13. Alves MJ, Ferreira IC, Dias J, Teixeira V, Martins A \& Pintado M (2007). A review on antimicrobial activity of a mushroom (Basidiomycetes) extracts and isolated compounds. Planta Med 16: 1707-1718.

14. Elsayed EA, El-Enshasy H, Wadaan MA \& Aziz R (2014). Mushrooms: a potential natural source of antiinflammatory compounds for medical applications. Mediators Inflamm 5: 2327. 